\title{
The effect of active hexose correlated compound on (multi) nodular euthyroid goiter: A double- blind placebo-controlled study
}

\author{
Zaure Zhaparkhanova ${ }^{1}$, Bayan Zhumanova ${ }^{2}$, Aziza Alipova ${ }^{2}$, Aizat Aimakhanova ${ }^{3}$, Sholpan Eslamgalieva ${ }^{4}$, \\ Anel Kurmanova ${ }^{1}$, Zhazira Nurlykaimova ${ }^{1}$, Michael Zeltser ${ }^{1}$, Assym Akyshbaev ${ }^{1}$ \\ ${ }^{1}$ Center of Neuroendocrinology, Almaty, Republic of Kazakhstan \\ ${ }^{2}$ Department of Endocrinology, S.D.Asfendiyarov Kazakh National Medical University, Almaty, Republic of Kazakhstan \\ ${ }^{3}$ Department of Biostatistics and Basic of Scientific Research, S.D.Asfendiyarov Kazakh National Medical University, Almaty, Republic of Kazakhstan \\ ${ }^{4}$ Department of Molecular Biology and Medical Genetics, S.D.Asfendiyarov Kazakh National Medical University, Almaty, Republic of Kazakhstan
}

Received: 2021-01-30.

Accepted: $2021-03-25$

This work is licensed under a Creative Commons Attribution 4.0 International License

J Clin Med Kaz 2021; 18(2):66-71

Corresponding author:

Zhaparkhanova Zaure.

E-mail: zaure-z@yandex.ru

\section{Abstract}

Aim: The aim of the study is to evaluate the effectiveness of Active Hexose Correlated Compound $\left(A \mathrm{HCC}^{\circledR}\right)$ use in monotherapy and its impact on the echographic characteristics of the thyroid gland during (multi) nodular goiter.

Material and methods: The study involved 27 people with (multi) nodular euthyroid goiter. The main treatment group consisted of 13 patients who received $\mathrm{AHCC} \otimes$. The placebo control group consisted of 14 participants. The duration of the drug intake lasted for 100 days. Three visiting schedules were arranged including initial, intermediate and final visits. Research methods included clinical examinations, laboratory tests, a thyroid ultrasound (classification by K-TIRADS) and completing a questionnaire.

Results: The laboratory tests confirmed the euthyroid status of patients in both groups at baseline and at the end of the study. A decrease in the total volume of the right and left lobes of the thyroid gland was noted among the main treatment group. In addition, a decrease in the volume of all types of nodules was seen in this group. A decrease in the volume of the type 2 colloid node was statistically significant. On the contrary, a statistically significant increase in the average volume of the same type of node among the control group was seen. Overall, the average volume of the node decreased by $37.2 \%$ in the main group and increased by $4.9 \%$ in the control group by the end of the study.

Conclusion: The results of this double-blind, placebo-controlled study make it possible to assess the efficiency of $A H C C \circledR$ in (multi) nodular goiter affecting primarily the volume of nodes (mainly of the 2 nd and 3rd types). This is especially important when a potential surgery or radioiodine therapy may carry a high risk of complications among patients.

Key words: (multi) nodular euthyroid goiter, ultrasound, Thyroid Image Reporting and Data System, Active Hexose Correlated Compound (AHCC)

\section{Introduction}

The importance of this study is related to high prevalence of the most common condition of the thyroid gland - (multi) nodular euthyroid goiter (MEG), especially in iodine-deficient regions $[1,2,3]$. There are no exact statistics on the prevalence of this condition and some studies suggest a $20-65 \%$ increase of its frequency with older age. This figure exceeds up to $50 \%$ according to ultrasound and autopsy data. Nodular forms may reach up to $50-70 \%$ of the population in endemic areas for goiter $[1,3]$.

The clinical concepts of "nodular goiter" or "multinodular goiter" combine single or multiple volumetric formations of the thyroid gland, different in morphology and detected by various diagnostic methods.

In most cases, nodal formations are harmless. Some patients may complain of a feeling of pressure in the neck, weakness, and a feeling of fear. Despite the 
seeming harmlessness, the thyroid nodes not only increase in size, causing compression of the surrounding organs, but also may lead to the formation of functional autonomy. In iodinedeficient regions, more often than in other territories, nodular goiter $(\mathrm{NG})$ can degenerate into malignant formations $[1,3]$.

The most common key method for diagnosing MEG and $\mathrm{NG}$ is a thyroid ultrasound, which allows to identify nodes from 2-3 mm. There are various methods of the thyroid gland visualization nowadays including TIRADS (Thyroid Image Reporting and Data System); first proposed in 2009 by Horvath E. et al, subsequently modified by Kwak et al in 2011 (K-TIRADS), the American College of Radiology (ACRTIRADS) and the European Thyroid Association (EU-TIRADS) $[4,5,6]$. According to Shi et al, the sensitivity of K-TIRADS is higher than that of ACR-TIRADS and EU-TIRADS, while ACR-TIRADS and EU-TIRADS have a higher specificity [6]. The creation of these thyroid imaging systems is intended to help with the diagnosis of nodal formations estimating the risk of malignancy in each category [7].

The treatment methods of MEG are inconclusive due to different approaches used in practice. The clinical significance of nodal formations is essentially limited by the need of excluding the oncological process. The treatment tactics of $\mathrm{NG}$ in accordance with the protocol for diagnosis and treatment of $\mathrm{NG}$ in adults, adopted in the Republic of Kazakhstan, depends on the results of fine-needle aspiration biopsy. In case of colloid goiter, an observation over the thyroid function and its size is required. In case of cancerous formations, a patient is usually referred to a different specialist [8]. At the same time, the commonly seen growth of nodes is accompanied by a deterioration in the wellbeing of patients and abnormalities in thyroid function.

A previously proposed TSH- suppressive therapy with levothyroxine was prescribed to prevent further growth of nodules in the thyroid gland by suppressing the secretion of thyroid stimulating hormone (TSH). Currently, given the risks of the TSH-suppressive therapy, researchers recommend some restrictions on its use $[2,4,9]$. To date, there are no methods of influencing the actual formation of thyroid nodules that have proven their effectiveness.

Within the framework of the principles of integrative medicine, the use of AHCC $\AA$, a standardized extract of the mushroom mycelium Lentinula edodes, produced by AminoUp (Japan), has become widespread. The AHCC $₫$ has been used in more than 45 countries for over 30 years. More than 100 studies have been published on the results of its application in various fields of medicine $[10,11]$. Considering the isolated studies on the use of AHCC ${ }^{\circledR}$ in thyroidology, it seems relevant to assess its effect on the course of NG and MEG.

A double-blind, placebo-controlled study to assess the effectiveness of AHCC $\AA$ in clinical management of $\mathrm{NG}$ and MEG in Kazakhstan was conducted for the first time.

The aim of this study is to evaluate the effectiveness of AHCC ${ }^{\circledR}$ in monotherapy and to assess its effect on the echographic characteristics of the thyroid gland during (multi) nodular goiter.

\section{Material and methods}

The study was conducted between February and June 2020. A total of 30 people were invited to participate in this study. The patients were randomly divided into two comparable groups. The control (placebo) group was prescribed the test food from the lot № 1 (placebo). The intervention group was prescribed the test food from lot № 2 (AHCC®) at a dose of $3000 \mathrm{mg}$ per day in the form of a food supplement registered in the Republic of Kazakhstan, $1500 \mathrm{mg}$ daily, twice a day before breakfast and before lunch. Neither the patient nor the investigator knew the contents of both lots.

The study was completed by 27 people. 3 people (suburbanites) dropped out of the study due to quarantine measures caused by the COVID 19 pandemic.

The control group consisted of 14 patients (12 females and 2 males) with an average age of $46.70 \pm 10.1$ years. The treatment (or intervention) group consisted of 13 patients (11 females and 2 males) with an average age of $49.85 \pm 12.5$ years.

Criteria for inclusion:

1. Men and women 30-70 years old with a diagnosed NG or MEG

2. Patients not taking medications, including iodine preparations and thyroid hormones at the beginning and before the end of the study

3. Patients who are able to adhere to the therapy regimen and follow the recommendations of the attending physician

4. Patients who signed the informed consent to participate in the study

Exclusion criteria:

1. Patients with severe somatic, oncological, mental illnesses

2. Pregnant and breastfeeding women

3. Patients under 30 and over 70 years old

4. Patients participating in other studies

The study was conducted at the Center for Neuroendocrinology, Almaty.

The visiting schedule included three visits. A clinical examinations, filling out a questionnaire, blood analysis, an ultrasound of the thyroid gland, prescription and dispensing of the test food from lot 1 or 2 were conducted during the initial visit. At the second intermediate visit, a clinical examination was performed including a thyroid ultrasound and filling out the questionnaires. The third final visit included a clinical examination, filling out the questionnaire, blood analysis, and ultrasound of the thyroid gland. The average follow-up time between the first and second visit was 53.1 days, and between the second interim and third final visit, 57.9 days. The total duration of observation was 109.9 days in the control group and 111.9 days in the treatment group. The lengthening of the observation period was caused by quarantine measures, which prevented the patients from getting to the study on time. The supply of test food from both lots and the duration of test food intake were 100 days.

The clinical examination included complaints and anamnesis, examination and assessment of clinical symptoms and a palpation of the thyroid gland at each visit. To assess the degree of thyroid enlargement by palpation, the generally accepted WHO classification (2001) was used, according to which 0,1 , and 2 degrees of enlargement were determined. In addition, the consistency of the node and its displacement were assessed by palpation, and the lymph nodes of the neck were examined.

Laboratory methods included determination of TSH, antibody titers to thyroglobulin ( $\mathrm{TgAb}$ ), antibody titers to thyroid peroxidase (TPOAb), free thyroxine (FT4) and calcitonin (CT) using solid phase chemiluminescence immunoassay.

A thyroid ultrasound was performed three times (at 1, 2, and 3 visits). The volume of the thyroid was calculated using a formula that takes into account the width, length and thickness of each lobe and the correction factor for ellipsoid. In addition, the ultrasound protocol included a description of the location and size of thyroid gland lesions and lymph nodes, taking 
into account the ultrasound characteristics. The K-TIRADS classification was used [5]. In all examined individuals, the ultrasound characteristics of the thyroid gland corresponded to the TI-RADS 2 category, which is not typical for thyroid cancer. A stationary device for ultrasound diagnostics "Siemens" ACUSON X-700 was used. A VF-12-4 linear probe was used to study thyroid tissues.

At each visit, all patients were asked to fill out a questionnaire, which included the answer options about the state of health based on 13 signs and measured on a 5-point scale. An informed consent was obtained from each patient.

The study was approved by the Local Ethics Commission of JSC "National Medical University" dated June 10, 2019, meeting No. 7 (84), (application No. 785)

The data analysis was conducted on Excel. Descriptive statistics was used for the quantitative parameters. If the distribution of the data was close to normal (determined by the Shapiro-Wilk test), then the comparison between the two indicators was performed using the paired Student's t test, otherwise Wilcoxon test was used. To determine the significance of the difference between the control and the main group, unpaired Student's t test was used for normally distributed data, otherwise the nonparametric Mann-Whitney test was used. The Pearson Chi-square test was used for analysis of categorical data.

To form the database, we used software created with the MS Excel spreadsheet processor. Further statistical processing of the data was carried out using the SPSS 13.0 package. Twosided criteria at a significance level of $\alpha=0.05$ was used for the statistical analysis.

\section{Results}

Most of the patients did not present any complaints and some of them developed non-specific symptoms. In some cases, discomfort in the neck area, an increase in its size, fatigue, and weakness was noted.

In accordance with the research plan, we carried out a comparative assessment of the average values of the studied laboratory parameters. The data on laboratory analysis of patients in the control and treatment groups are presented in Table 1.

According to the results of laboratory tests, the initial euthyroid status remained the entire observation period in patients of both groups. To assess the echographic parameters in patients of both groups, the results of a thyroid ultrasound were analyzed. A comparison of such basic indicators as the total volume of the thyroid gland and the volume of its right and left lobes was carried out and presented in Table 2.

Table 1

Laboratory tests results of both groups (average values)

\begin{tabular}{|l|l|l|l|}
\hline Indicators & Groups & Initial visit & Final visit \\
\hline \multirow{2}{*}{ TSH $(0,4-4,0 \mathrm{mIU} / \mathrm{L})$} & Main & $1,57 \pm 0,87$ & $1,78 \pm 0,85$ \\
\cline { 2 - 4 } & Control & $1,55 \pm 0,84$ & $1,42 \pm 0,75$ \\
\hline \multirow{2}{*}{ FT4 $(9,0-19,05 \mathrm{pmol} / \mathrm{L})$} & Main & $12,64 \pm 1,89$ & $11,99 \pm 1,11$ \\
\cline { 2 - 4 } & Control & $13,14 \pm 1,88$ & $12,49 \pm 0,89$ \\
\hline \multirow{2}{*}{ TGAb $(<18,0 \mathrm{IU} / \mathrm{ml})$} & Main & $3,0(3,0 ; 3,0)$ & $3,0(3,0 ; 3,6)$ \\
\cline { 2 - 4 } & Control & $3,0(3,0 ; 7,75)$ & $3,0(3,0 ; 25,55)$ \\
\hline \multirow{2}{*}{ CT $(<8,4 \mathrm{pg} / \mathrm{ml})$} & Main & $3,0(3,0 ; 3,0)$ & $3,0(3,0 ; 3,0)$ \\
\cline { 2 - 4 } & Control & $3,0(3,0 ; 3,0)$ & $3,0(3,0 ; 3,0)$ \\
\hline & Main & $2,0(2,0 ; 2,0)$ & $2,0(2,0 ; 2,0)$ \\
\cline { 2 - 4 } & Control & $2,0(2,0 ; 2,25)$ & $2,0(2,0 ; 2,0)$ \\
\hline
\end{tabular}

As it can be seen from the table, the studied parameters in treatment and control groups at the start of the study did not differ statistically. The initially larger thyroid volume in the control group is explained by the inclusion in this group of a patient with an abnormal initial total thyroid volume of $130 \mathrm{~cm} 3$. Compliance of the patient's data with the inclusion criteria of the study allowed us considering the results of this specific patient's data. However, due to the extreme values, we also analyzed the results without the outliers. Recommendations for the statistical analysis of medical data require the analysis to be performed twice (with outliers and then without) $[12,13]$. At the initial visit, comparison of similar indicators of the treatment group with the control group without outliers also did not reveal significant differences.

At the second interim visit, the volume of the left lobe slightly increased in patients in the treatment group. In the control group, the volume of the right lobe increased. In patients of the control group without outliers, an increase in all studied parameters was noted. The differences between the groups remained insignificant.

By the end of the study, all the study parameters in the intervention group decreased. There was also an increase in all three indicators in the control group including the control group without outliers. However, a statistically significant decrease in the main group was revealed in relation to a decrease in the volume of only the left lobe $(\mathrm{p}=0.033)$. The dynamics of changes in the total volume of nodes is analyzed (Table 3 ).

In the control group, the initial mean total volume of nodes, which amounted to $6.14(6.08 ; 0.63) \mathrm{cm} 3$, slightly increased at the intermediate visit to $6.19(0.45 ; 6.8) \mathrm{cm} 3$ and reached 6.46 by the end of the observation $(0.4 ; 6.8) \mathrm{cm} 3$. An increase in the average total volume of nodes from $3.09(0.55 ; 3.9) \mathrm{cm} 3$ to 3.25 $(0.4 ; 4.4) \mathrm{cm} 3$ occurred in the control group without outliers.

Only the main group showed positive dynamics. The average volume of nodes in the main group, which initially amounted to $3.45(2.7 ; 5.2) \mathrm{cm} 3$, significantly decreased to 2.92 $(0.3 ; 4.75) \mathrm{cm} 3$ at the intermediate visit and decreased even more by the end of observation to $2.17(0.3 ; 4.5) \mathrm{cm} 3$.

During the indicated observation period, we analyzed the ultrasound characteristics of various types of identified nodes type 1 colloidal nodes (CN1), Hashimoto type 1 pseudo-nodes (CNH), type 2 colloidal nodes (CN2), type 3 colloidal nodes (CN3) of the K-TIRADS2 category. The data on ultrasound characteristics of the thyroid gland formations in the control group are presented in Table 4.

In patients of the control group, the largest volume fell on types CN2 and CN3. By the end of the study, all types of nodes retained their original volume. At the same time, the volume of CN2 significantly increased from $1.2(0.375 ; 3.825) \mathrm{cm} 3$ to 1.75 $(0.825 ; 6.975) \mathrm{cm} 3$ by the end of the observation $(\mathrm{p}=0.028)$. The decrease in the volumes of $\mathrm{CNH}$ and $\mathrm{CN} 3$ was not statistically significant.

In patients of the control group without outliers, a similar significantly significant ( $\mathrm{p}=0.043)$ increase in CV2 was revealed from $1.1(0.35 ; 1.85)$ to $1.5(0.65 ; 4.4)$. The decrease in the volume of $\mathrm{CN} 3$ and $\mathrm{CNH}$ was not statistically significant.

In the main group, the largest initial volume also fell on the types CN3 and CN2. There is an obvious tendency towards a decrease in the volume of all types of nodules. In particular, the volume of CN1 decreased from $0.1(0.0 ; 0.2) \mathrm{cm} 3$ to $0.0(0.0$; $0.1) \mathrm{cm} 3$. The volume of CN2 significantly decreased by the end of the observation from $1.8(0.6 ; 4.2) \mathrm{cm} 3$ to $1.05(0.325 ; 3.8)$ $\mathrm{cm} 3$. The volume of $\mathrm{CN} 3$ decreased by almost half, and by the end of the observation, $\mathrm{CNH}$ was not detected at all. 


\begin{tabular}{|c|c|c|c|c|c|c|c|c|c|c|c|c|}
\hline \multirow{3}{*}{$\begin{array}{l}\text { Indicators } \\
(\mathrm{cm} 3)\end{array}$} & \multicolumn{4}{|c|}{ Initial visit } & \multicolumn{4}{|c|}{ Intermediate visit } & \multicolumn{4}{|l|}{ Final visit } \\
\hline & 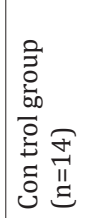 & 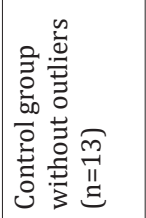 & 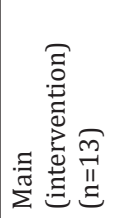 & $\mathrm{p}$ & 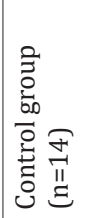 & 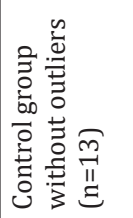 & 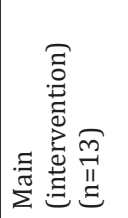 & $\mathrm{p}$ & 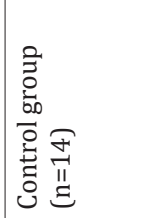 & 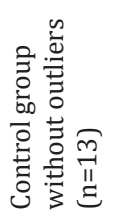 & 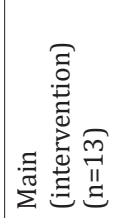 & $\mathrm{p}$ \\
\hline & 1 & 2 & 3 & & 1 & 2 & 3 & & 1 & 2 & 3 & \\
\hline $\begin{array}{l}\text { Total } \\
\text { thyroid } \\
\text { volume }\end{array}$ & $\begin{array}{l}13,9 \\
(11,0 \\
31,43)\end{array}$ & $\begin{array}{l}13,2 \\
(10,8 ; 24,4)\end{array}$ & $\begin{array}{l}12,9 \\
(9,3 ; \\
18,8)\end{array}$ & $\begin{array}{l}\mathrm{p}^{1 \cdot 3}>0,05 \\
\mathrm{p}^{2 \cdot 3}>0,05\end{array}$ & $\begin{array}{l}16,35 \\
(14,1 ; \\
35,58)\end{array}$ & $\begin{array}{l}15,9 \\
(13,3 ; \\
28,3)\end{array}$ & \begin{tabular}{|l|}
13,0 \\
$(10,75 ;$ \\
$17,15)$
\end{tabular} & $\begin{array}{l}\mathrm{p}^{1-3}>0,05 \\
\mathrm{p}^{2-3}>0,05\end{array}$ & $\begin{array}{l}16,6 \\
(13,03 ; \\
36,4)\end{array}$ & $\begin{array}{l}16,4 \\
(12,35 ; \\
31.55)\end{array}$ & $\begin{array}{l}13,3 \\
(11,0 ; \\
16,05)\end{array}$ & $\begin{array}{l}\mathrm{p}^{1-3}>0,05 \\
\mathrm{p}^{2 \cdot 3}>0,05\end{array}$ \\
\hline $\begin{array}{l}\text { The } \\
\text { volume } \\
\text { of the left } \\
\text { lobe }\end{array}$ & $\begin{array}{l}7,05 \\
(4,95 \\
11,68)\end{array}$ & $\begin{array}{l}6,2 \\
(4,9 ; \\
10,2)\end{array}$ & \begin{tabular}{|l}
5,1 \\
$(3,35 ;$ \\
$8,25)$
\end{tabular} & $\begin{array}{l}\mathrm{p}^{1-3}>0,05 \\
\mathrm{p}^{2-3}>0,05\end{array}$ & $\begin{array}{l}7,85 \\
(5,73 ; \\
14,88)\end{array}$ & $\begin{array}{l}7,3 \\
(5,65 ; \\
13,9)\end{array}$ & \begin{tabular}{|l}
4,9 \\
$(3,7 ; 9,4)$
\end{tabular} & $\begin{array}{l}\mathrm{p}^{1-3}>0,05 \\
\mathrm{p}^{2-3}>0,05\end{array}$ & $\begin{array}{l}7,5 \\
(5,7 ; 16,4)\end{array}$ & $\begin{array}{l}7,4 \\
(5,7 ; 15,4)\end{array}$ & $\begin{array}{l}4,9 \\
(3,3 ; 9.25)\end{array}$ & $\begin{array}{l}\mathrm{p}^{1-3}>0,05 \\
\mathrm{p}^{2-3}>0,05\end{array}$ \\
\hline $\begin{array}{l}\text { The } \\
\text { volume of } \\
\text { the right } \\
\text { lobe }\end{array}$ & $\begin{array}{l}7,65 \\
(4,83 ; \\
13,2)\end{array}$ & $\begin{array}{l}7,2 \\
(4,75 ; 10,9)\end{array}$ & $\begin{array}{l}7,94 \pm \\
3,48\end{array}$ & \begin{tabular}{|l|}
$\mathrm{p}^{1-3}>0,05$ \\
$\mathrm{p}^{2-3}>0,05$
\end{tabular} & $\begin{array}{l}12,66 \pm \\
9,13\end{array}$ & $\begin{array}{l}8,4 \\
(6,2 ; 14,1)\end{array}$ & $\begin{array}{l}7,2 \\
(6,25 ; 8,5)\end{array}$ & $\begin{array}{l}\mathrm{p}^{1-3}>0,05 \\
\mathrm{p}^{2-3}>0,05\end{array}$ & $\begin{array}{l}8,5 \\
(6,0 ; 21,38)\end{array}$ & $\begin{array}{l}8,2 \\
(5,3 ; \\
18,65)\end{array}$ & $\begin{array}{l}7,49 \pm \\
2,11\end{array}$ & $\begin{array}{l}\mathrm{p}^{1-3}>0,05 \\
\mathrm{p}^{2-3}>0,05\end{array}$ \\
\hline
\end{tabular}

Table 3 Average volume of nodes $(\mathrm{cm} 3)$ during the study period

\begin{tabular}{|l|l|l|l|l|}
\hline Groups & Initial visit & Intermediate visit & Final visit & $\mathrm{p}$ \\
\cline { 2 - 5 } & 1 & 2 & 3 & $1,75(0,4 ; 6,98)$ \\
\hline Control group (n=14) & $1,3(0,63 ; 6,08)$ & $1,35(0,45 ; 6,8)$ & $\begin{array}{l}\mathrm{p}^{1-3}>0,05 \\
\mathrm{p}^{2-3}>0,05\end{array}$ & $\begin{array}{l}\mathrm{p}^{1-3}>0,05 \\
\mathrm{p}^{2-3}>0,05\end{array}$ \\
\hline Control group without outliers $(\mathrm{n}=13)$ & $1,3(0,55 ; 3,9)$ & $1,3(0,4 ; 4,6)$ & $1,5(0,4 ; 4,4)$ & $\begin{array}{l}\mathrm{p}^{1-3}=0,036 \\
\mathrm{p}^{2-3}=0,021\end{array}$ \\
\hline Main (intervention) group (n=13) & $2,7(0,7 ; 5,2)$ & $1,5(0,6 ; 4,75)$ & $1,1(0,3 ; 4,5)$ & \\
\hline
\end{tabular}

Table 4 Dynamics of changes in the volumes of various types of thyroid nodules at different periods of the study

\begin{tabular}{|c|c|c|c|c|c|c|c|c|c|c|c|c|}
\hline \multirow{3}{*}{$\begin{array}{l}\text { Indicators } \\
(\mathrm{cm} 3)\end{array}$} & \multicolumn{4}{|c|}{ Control group $(n=14)$} & \multicolumn{4}{|c|}{ Control group without outliers ( $\mathrm{n}=13$ ) } & \multicolumn{4}{|c|}{ Main (intervention) group $(\mathrm{n}=13)$} \\
\hline & 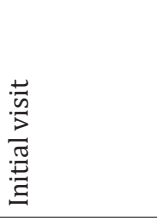 & 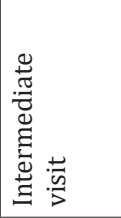 & 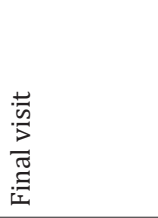 & $\mathrm{p}$ & 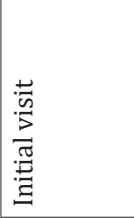 & 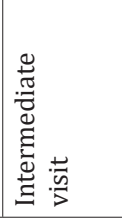 & 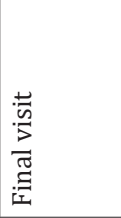 & $\mathrm{p}$ & 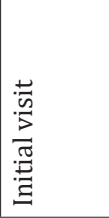 & 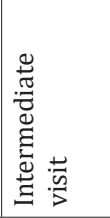 & 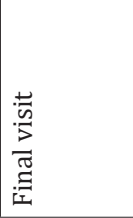 & $\mathrm{p}$ \\
\hline & 1 & 2 & 3 & & 1 & 2 & 3 & & 1 & 2 & 3 & \\
\hline CN1 & $\begin{array}{l}0,0 \\
(0,0 ; 0,0)\end{array}$ & $\begin{array}{l}0,0 \\
(0,0 ; 0,05)\end{array}$ & \begin{tabular}{|l|}
0,0 \\
$(0,0 ; 0,0)$
\end{tabular} & $\mathrm{P}^{3-1}>0,05$ & \begin{tabular}{|l|}
0,0 \\
$(0,0 ; 0,0)$
\end{tabular} & \begin{tabular}{|l|}
0,0 \\
$(0,0 ; 0,0)$
\end{tabular} & $\begin{array}{l}0,0 \\
(0,0 ; 0,0)\end{array}$ & & $\begin{array}{l}0,1 \\
(0,0 ; 0,2)\end{array}$ & \begin{tabular}{|l|}
0,0 \\
$(0,0 ; 0,2)$
\end{tabular} & \begin{tabular}{|l|}
0,0 \\
$(0,0 ; 0,1)$
\end{tabular} & $\mathrm{P}^{3-1}>0,05$ \\
\hline $\mathrm{CNH}$ & $\begin{array}{l}0,5 \\
(0,3 ; 0,7)\end{array}$ & $\begin{array}{l}0,5 \\
(0,5 ; 05)\end{array}$ & $\begin{array}{l}0,4 \\
(0,4 ; 0,4)\end{array}$ & $\mathrm{p}^{3-1}>0,05$ & $\begin{array}{l}0,7 \\
(0,7 ; 0,7)\end{array}$ & - & - & & $\begin{array}{l}0,1 \\
(0,1 ; 0,1)\end{array}$ & - & - & \\
\hline $\mathrm{CN} 2$ & $\begin{array}{l}1,2 \\
(0,375 ; 3,825)\end{array}$ & $\begin{array}{l}1,2 \\
(0,5 ; 6,6)\end{array}$ & $\begin{array}{l}1,75 \\
(0,825 ; 6,975)\end{array}$ & $\mathrm{p}^{3-1}=0,028$ & $\begin{array}{l}1,1 \\
(0,35 ; 1,85)\end{array}$ & \begin{tabular}{|l}
1,1 \\
$(0,45 ; 3,6)$
\end{tabular} & \begin{tabular}{|l|}
1,5 \\
$(0,65 ; 4,4)$
\end{tabular} & $P^{3 \cdot 1}=0,043$ & $\begin{array}{l}1,8 \\
(0,6 ; 4,2)\end{array}$ & $\begin{array}{l}1,5 \\
(0,6 ; 4,6)\end{array}$ & \begin{tabular}{|l|}
1,05 \\
$(0,325 ; 3,8)$
\end{tabular} & $\begin{array}{l}\mathrm{P}^{2-3}=0,021 \\
\mathrm{P}^{1-3}=0,037\end{array}$ \\
\hline CN3 & $\begin{array}{l}5,4 \\
(1,7 ; 16,6)\end{array}$ & $\begin{array}{l}8,2 \\
(1,7 ; 14,7)\end{array}$ & $\begin{array}{l}2,0 \\
(0,4 ; 16,1)\end{array}$ & $\mathrm{p}^{3-1}>0,05$ & $\begin{array}{l}5,4 \\
(1,7 ; 16,6)\end{array}$ & \begin{tabular}{|l}
8,2 \\
$(1,7 ; 14,7)$
\end{tabular} & \begin{tabular}{|l}
2,0 \\
$(0,4 ; 16,1)$
\end{tabular} & $\mathrm{P}^{3-1}>0,05$ & $\begin{array}{l}6,45 \\
(5,4 ; 7,5)\end{array}$ & \begin{tabular}{|l|}
4,9 \\
$(4,9 ; 4,9)$
\end{tabular} & \begin{tabular}{|l}
3,4 \\
$(3,4 ; 3,4)$
\end{tabular} & $\mathrm{P}^{3-1}>0,05$ \\
\hline
\end{tabular}

Table 5 shows the results of the survey, in which the patients of the control and main groups self- assessed health according to a 5-point system. For statistical processing, the Pearson Chisquare test was used. The following indicators were assessed: appetite, weakness, mood, palpitations, constipation or diarrhea, tension in the eyes, a tendency to infections, ringing in the ears, dry skin, headaches, malaise and neck circumference.

In the main group, significant $(p=0.026)$ improvement was noted for such a sign as palpitation. At the final visit, 10 participants $(76.92 \%)$ noted this sign by 4 and 5 points in the main group, and only 2 participants in the control group $(14.28 \%)$. Other 3 patients of the main group (23.08\%) and 10 participants $(71.44 \%)$ of the control group rated this sign at 3 points.

In the main group, there was also statistically significant improvement $(\mathrm{p}=0.014)$ in terms of headaches: 9 participants of the main group $(69.23 \%)$ noted this feature at 4 and 5 points, while in the control - only 2 people (14.28\%) reported the improvement. Other 4 participants $(30.77 \%)$ of the main group and 8 participants $(57.15 \%)$ of the control group noted a satisfactory state on this basis.

Statistically significant $(p=0.015)$ improvement in the main group was also revealed for such a sign as ringing in the ears (tinnitus): 10 participants in the main $(76.92 \%)$ and 3 


\begin{tabular}{|c|c|c|c|c|c|c|c|}
\hline \multirow[t]{2}{*}{ Indicators } & \multirow[t]{2}{*}{ Groups } & \multicolumn{5}{|c|}{ Scores (n\%) } & \multirow[t]{2}{*}{$\mathrm{p}$} \\
\hline & & 1 & 2 & 3 & 4 & 5 & \\
\hline \multirow[t]{2}{*}{ Palpitation } & $\begin{array}{l}\text { Control } \\
(\mathrm{n}=14)\end{array}$ & $1(7,14)$ & $1(7,14)$ & $10(71,44)$ & $1(7,14)$ & $1(7,14)$ & $\mathrm{p}=0,026$ \\
\hline & $\begin{array}{l}\text { Main } \\
(\mathrm{n}=13)\end{array}$ & - & - & $3(23,08)$ & $5(38,46)$ & $5(38,46)$ & \\
\hline \multirow[t]{2}{*}{ Headache } & $\begin{array}{l}\text { Control } \\
(\mathrm{n}=14)\end{array}$ & - & $4(28,57)$ & $8(57,15)$ & $2(14,28)$ & - & $\mathrm{p}=0,014$ \\
\hline & $\begin{array}{l}\text { Main } \\
(\mathrm{n}=13)\end{array}$ & - & - & $4(30,77)$ & $5(38,46)$ & $4(30,77)$ & \\
\hline \multirow[t]{2}{*}{ Tinnitus } & $\begin{array}{l}\text { Control } \\
(\mathrm{n}=14)\end{array}$ & - & - & $11(78,58)$ & $1(7,14)$ & $2(14,28)$ & $\mathrm{p}=0,015$ \\
\hline & $\begin{array}{l}\text { Main } \\
(\mathrm{n}=13)\end{array}$ & - & - & $3(23,08)$ & $4(30,77)$ & $6(46,15)$ & \\
\hline \multirow[t]{2}{*}{ Constipation } & $\begin{array}{l}\text { Control } \\
(\mathrm{n}=14)\end{array}$ & - & - & $12(85,72)$ & $1(7,14)$ & $1(7,14)$ & $\mathrm{p}=0,001$ \\
\hline & $\begin{array}{l}\text { Main } \\
(\mathrm{n}=13)\end{array}$ & - & $2(15,38)$ & $1(7,7)$ & $7(53,84)$ & $3(23,08)$ & \\
\hline
\end{tabular}

participants in the control group $(21.42 \%)$ assessed this feature at 4 and 5 points by the end of the observation. This feature was assessed as satisfactory by 3 participants in the main group $(23.08 \%)$ and 11 participants $(78.58 \%)$ in the control group.

According to such a sign as the nature of the stool (the presence of constipation), a significantly significant $(p=0.001)$ improvement was also revealed by the end of observation in the main group: 10 participants $(76.92 \%)$ noted this feature at 4 and 5 points, while in the control - only $2(14.28 \%)$ participants reported the improvement; 1 participant $(7.7 \%)$ of the main group and 12 participants $(85.72 \%)$ of the control group rated this feature as satisfactory.

According to the other 9 signs, by the end of the observation, there was a tendency towards improvement in the condition in the patients of the main group, but not statistically significant difference with the control group was revealed.

\section{Discussion}

The number of patients with NG and MEG in endemic regions tends to grow. The territory of Kazakhstan is an endemic zone for iodine deficiency. The search for more advanced treatment methods of $\mathrm{NG}$ and MEG in iodine-deficient regions is an urgent task due to the existing methods being not effective enough. The results of this double-blind, placebo-controlled study were obtained by comparing homogeneous by number of observations, age and gender groups.

In both groups, the diagnosis was made in accordance with the protocol for the diagnosis and treatment of NG, adopted in the Republic of Kazakhstan [8]. The diagnosis of each patient included in the study met the required criteria.

An evaluation of clinical symptoms, carried out at each examination, indicated the euthyroid status of patients in both groups throughout the study period. The main part consisted of patients with a degree 1 thyroid enlargement. To a lesser extent with normal volume and a grade 2 thyroid enlargement. In some patients, the consistency of the nodes and their displacement were assessed by palpation.

The laboratory data confirmed the euthyroid status of patients in both groups, both at baseline and at the end. The CT content, which was within the reference values for the entire observation period, indirectly indicated a low probability of thyroid cancer in all patients. The ultrasound characteristics corresponded to the K-TIRADS2 category, which is not a characteristic of thyroid cancer.
By the end of the entire observation period, in the main treatment group, there was a slight decrease not only in the total volume, but also in both thyroid lobes. In the control group, on the contrary, there was an increase in the total volume of the thyroid gland and its right lobe. In the control group, without taking into account the outliers, an increase was noted not only in the total volume, but also in both of its shares. However, when comparing the indicators, a statistically significant decrease in the main group was revealed in relation to a decrease in the volume of only the left lobe $(p=0.033)$. We revealed a statistically significant decrease in the average volume of nodes in the main treatment group from $3.45(2.7 ; 5.2) \mathrm{cm} 3$ to 2.17 $(0.3 ; 4.5) \mathrm{cm} 3$ by the end of the observation, as an evidence of AHCC®'s positive effect.

There are no generally accepted criteria for evaluating the growth or shrinkage of a node using ultrasound. There is no agreement on how to define significant growth or reduction of nodes. The American Thyroid Association guidelines suggest that growth be defined as an increase in two of the three node sizes by at least $20 \%$ with a minimum increase in area of at least $2 \mathrm{~mm} 2$. Such criteria correspond to an increase in the volume of the node by at least $44 \%$, which allows one to estimate the real change in size [14].

We revealed a statistically significant decrease in the average volume of nodes from $3.45(2.7 ; 5.2) \mathrm{cm} 3$ to 2.17 $(0.3 ; 4.5) \mathrm{cm} 3$ by the end of the study, which amounted to $37.2 \%$ and may indicate a significant positive effect of this test food. In contrast, taking placebo resulted in a $4.9 \%$ increase in mean total nodule volume. In a study by Grussendorf M. et al [15], even the combined use of L-thyroxine and iodide reduced the volume of nodes by only $21.6 \%$. In monotherapy with L-thyroxine, there was a decrease in the volume of nodes by $12.6 \%$, with iodide by $9 \%$. Baldini M. [16] et al reported a decrease in the volume of nodes on monotherapy with L-thyroxine by more than $30 \%$ in only $26 \%$ of patients, no changes in $67 \%$ of patients, an increase in the size or the appearance of new nodes in $7 \%$ of treated patients.

Ultrasound allows to determine not only the volume of nodes, but also to identify their characteristics. It is generally accepted that the most effective use of five (TIRADS1TIRADS5) standard categories of conclusions of the international classification K-TIRADS.

According to the classification, category K-TIRADS2 includes benign changes. The various echo-morphological types 
of nodes in this category include $\mathrm{CN} 1, \mathrm{CNH}, \mathrm{CN} 2$ and $\mathrm{CN} 3$. In accordance with this, an assessment of thyroid ultrasound was carried out among this study participants.

According to the results of our study, a decrease in the volume of all types of nodules was revealed in the main (intervention) group. At the same time, a decrease in the volume of CN2 was also statistically significant. On the contrary, in the control group, the volume of CN2 significantly increased by the end of the study.

The general trend for all 27 patients of both groups is an improvement in their well-being, a decrease in the number of unsatisfactory assessments. It is also possible that an increase in the "excellent" scores is due to the "placebo" effect in the control group. This phenomenon shows that a placebo, which a patient takes for a drug, has a positive effect in about a third of patients in the study [12]. However, the best effect according to the survey data on the well-being of patients was provided by taking AHCC $®$. Signs such as palpitations, headaches, ringing in the ears, constipation showed a significantly significant improvement in patients of the main group in comparison with the control group.

All patients who received AHCC $\AA$ noted an increase in performance, a decrease in neck circumference, a normalization of blood pressure, a low susceptibility to respiratory diseases, and a decrease in weakness. No undesirable side effects were observed in any group of patients who completed the study in any case.

\section{Conclusion}

This double-blind, placebo-controlled study allowed obtaining results that indicate the possibility of increasing the effectiveness of treatments for patients with NG and MEG.

AHCC $®$ is known to have a wide range of effects on the immune system. It has been found to have a significant effect on the survival rate of patients with lung cancer, bladder cancer and melanoma [10]. The antitumor effect of AHCC $₫$ may be partially mediated by modulation of T-cell function. The effect of

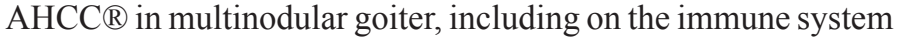
in this disease, has not been studied. More research is needed to investigate the immunological effects and mechanisms that may lead to a deeper understanding of the mechanism of action of AHCC ${ }^{\circledR}$ in (multi) nodular euthyroid goiter. This clinical study can be considered as preliminary and further supplemented by a large number of observations and experimental studies.

Thus, according to the results of this double-blind, placebocontrolled study, it can be noted that the use of AHCC ${ }^{\circledR}$ is effective and can be recommended for the treatment of $\mathrm{NG}$ and MEG. The drug has shown high efficiency in terms the volumes of nodes. This is especially important when possible surgery or radioiodine therapy may carry a high risk of complications among patients.

Disclosures: There is no conflict of interest for all authors. Acknowledgements: None.

Funding: Sponsor of the study: Amino Up Co., Ltd (Japan)

\section{References}

1. Balabolkin M.I., Klebanova E.M., Kreminskaja V.M. Fundamental'naja i klinicheskaja tiroidologija (Fundamental and Clinical Thyroidology) [in Russian] M, 2007. 816 p.

2. Valdina E.A. Zabolevanija shhitovidnoj zhelezy: Rukovodstvo (Thyroid Disorders: A Guide) [in Russian]. 3th ed. Spb, 2006,368 p.

3. Jendokrinologija. Nacional'noe rukovodstvo. Kratkoe izdanie (Endocrinology. National leadership. Short edition) [in Russian] /pod red. I.I.Dedova, G.A.Mel'nichenko. 2nd ed. M, 2018. 832 p.

4. Horvath E, Majlis S, Rossi R, Franco C, Niedmann J.P., Castro A. et al. An ultrasonogram reporting system for thyroid nodules stratifying cancer risk for clinical management. The Journal of Clinical Endocrinology\&Metab. 2009; 94(5):1748-1751.

5. Kwak J.Y., Han K.H., Yoon J.H., Moon H.J., Son E.J., Park S.H. et al. Thyroid imaging reporting and data system for US features of nodules: a step in establishing better stratification of cancer risk. Radiology. 2011; 260(3): 892-899.

6. Shi Yi-Xin, Chen Lin, Liu Ying-Chun, Zhan Jia, Diao Xue-Hong, Fang Liang et al. Differences among the Thyroid Imaging Reporting and Data System proposed by Korean, the American College of Radiology and the European Thyroid Assosiation in the diagnostic performance of thyroid nodules. Translational Cancer Research. 2020; 9(8):4958-4967. Doi:10.21037/tcr-19-2870

7. Schenke S., Klett R., Seifert P., Kreissl MC, Gorges R., Zimny M. Diagnostic Performance of Different Thyroid Imaging Reporting and Data Systems (Kwak-TIRADS, EU-TIRADS and ACR TIRADS) for the Risk Stratification of Small Thyroid Nodules ( $\leq 10 \mathrm{~mm}$ ). Journal of Clinical Medicine. 2020; 9(1). DOI:10.3390/jcm9010236

8. Klinicheskij protokol diagnostiki i lechenija «Uzlovoj zob u vzroslyh» (Clinical protocol for diagnosis and treatment "Nodular goiter in adults") [in Russian], RCRZ, protokol № 8 ot 13.07.2016. www.rcrz.kz.

9. Rossijskie klinicheskie rekomendacii. Jendokrinologija (Russian clinical guidelines. Endocrinology) [in Russian] /pod red. I.I.Dedova, G.A.Mel'nichenko. M, 2019. 592 p.

10. Clinician's Guide to AHCC®/ edited by Kulkarni AD, Calder P, Ito T. Published by ICNIM, Hokkaido, 2017. 300 p.

11. Shin Min Sun, Park Hong-Jai, Maeda Takahiro, Nishioka Hiroshi, Hajime Fujii, Insoo Kang The Effects of AHCC ${ }^{\circledR}$, a Standardized Extract of Cultured Lentinula edodes Mycelia, on Natural Killer and T Cells in Health and Disease: Reviews on Human and Animal Studies. Journal of Immunology Research. 2019. https://doi.org/10.1155/2019/3758576

12. Rebrova O.Ju. Statisticheskij analiz medicinskih dannyh. Primenenie paketa prikladnyh programm STATISTICA (Statistical analysis of medical data. Using the STATISTICA Application Package) [in Russian] M, 2002, 312 p.

13. Fletcher R., Fletcher S., Vagner Je. Klinicheskaja jepidemiologija: Osnovy dokazatel'noj mediciny (Clinical Epidemiology: Basics of Evidence-Based Medicine) [in Russian] M, 1998. 352 p.

14. Ul'trazvukovoe issledovanie shhitovidnoj zhelezy (Thyroid ultrasound) [in Russian]/red.: G.Dzhek Bjeskin-st., Djeniel S. Djuik, Robert Je.Levin. M, 2018. 432 p.

15. Grussendorf M, Reiners C, Paschke R, Wegscheider K. Reduction of thyroid nodule volume by levothyroxine and jodine alone and in combination: A randomized, placebo-controlled trial. J Clin Endocrinol Metab. 2011; 96:2786-95

16. Baldini, M; Gallazzi, M; Orsatti, A; Fossati, S; Leonardi, P; Cantalamessa L. Treatment of benign nodular goiter with mildly suppressive doses of L-thyroxine: effects on bone mineral density and on nodule size. Journal of internal medicine. 2002; 251(5):407-414 